\title{
Evaluation of Different Methods of Bladder Drainage Used in the Early Care of Spinal Cord Injury Patients
}

J. J. Wyndaele, M.D., ${ }^{1}$ W. A. De Sy, M.D., ${ }^{1}$ and H. Claessens, M.D. ${ }^{2}$

${ }^{1}$ Department of Urology and ${ }^{2}$ S.C.I. Service, State University of Ghent, Belgium

\section{Summary}

In a series of 115 spinal cord injury patients four different methods of bladder drainage were used mainly during spinal shock. That is a) suprapubic fine bore cystostomy, b), indwelling Foley catheter, c) intermittent catheterisation; and $d$ ) both last methods consecutively.

The methods of bladder drainage used did not influence the number of patients becoming catheterfree but determined significantly the length of period before patients became catheterfree. Patients on intermittent catheterisation had the shortest time from injury to established micturition.

Patients on intermittent catheterisation and on cystostomy had few complications but in those patients treated with an indwelling Foley catheter the complication rate was high.

Key words: Spinal cord injury; Spinal shock; Urinary bladder drainage.

\section{Introduction}

The search for an ideal method of bladder drainage in paraplegics during the period of spinal shock has continued since Curling (1833) described the dangers of catheterisation in such patients. Different methods have been tried, such as cystostomy (Hugonet and Dejerine, 1919), manual expression (Besley, 1917; Vellacott, 1919), tidal drainage (Munro and Hahn, 1935), intermittent catheterisation (Guttmann and Frankel, 1966). Most of these methods are still used today and results have been published recently (Grundy et al., 1983; Marosszeky 1973; Verschueren, 1982).

Here we report our experience with four different methods of bladder drainage used during spinal shock.

\section{Patients and methods}

One hundred and fifteen patients were studied (92 men and 23 women). The 
mean age of the women was 42 years, that of the men being 34 years. Seventy per cent were paraplegics and 30 per cent tetraplegics. The spinal cord lesion was caused by trauma in 83 per cent of the patients. Seventeen per cent of the patients had a spinal lesion due to a medical cause. The methods of bladder drainage applied during spinal shock are given in Table 1.

Table 1 Methods of bladder drainage used during spinal shock

\begin{tabular}{|c|c|c|c|}
\hline Method of bladder drainage & Paraplegic & $\begin{array}{l}\text { No. patients } \\
\text { Tetraplegic }\end{array}$ & Total \\
\hline Indwelling Foley catheter (F.C.) & 39 & 20 & 59 \\
\hline Intermittent catheterisation (I.C.) & 19 & 9 & 28 \\
\hline Foley catheter + Interm. cathet. (F.C. + I.C.) & 15 & 5 & 20 \\
\hline Suprapubic cystostomy (S.P.C.) & 3 & 2 & 5 \\
\hline Suprap. cyst. + interm. catheter. (S.P.C. + I.C.) & 1 & - & 1 \\
\hline Unknown & 2 & - & 2 \\
\hline Total No. patients & 79 & 36 & 115 \\
\hline
\end{tabular}

Ninety-two patients had a single method of bladder drainage during the entire primary treatment. In 20 patients intermittent catheterisation was started after an initial period of indwelling Foley catheter drainage. In one patient intermittent catheterisation had to be stopped because of urethral trauma. Therefore drainage by suprapubic cystostomy was used. In two patients several of the methods were used but our information on these patients is incomplete.

A number of patients had, in the post-traumatic period, a Foley catheter for less than 3 days before intermittent catheterisation was started. These patients were considered to belong to the group who had been treated solely by intermittent catheterisation.

\section{Results}

The following aspects were studied:

1. Influence of the method of bladder drainage on the number of patients becoming catheterfree

In tracing such influence a number of patients had to be excluded. For example, five patients died early or went to another centre before re-education was completed. Eleven patients regained complete normal bladder and urethral function, their evolution being based mainly on their neurological recuperation. In another twelve patients other factors were of influence (Table 2).

Results are compared in 87 patients (Table 3). Statistically there is no significant difference between the groups of patients treated with different methods (Chi-Square test-Exact Fisher test).

2. Influence of the method of bladder drainage on the length of period before patients became catheterfree

Only patients becoming completely catheterfree were considered for this comparison. 
Table 2 Patients in whom additional factors influenced their not becoming independent of a urinary catheter

\begin{tabular}{lc}
\hline & No. patients \\
\hline Refusal of surgical treatment of lower urinary tract (sphincterotomy, prostate resection) & 4 \\
Personal preference of a Foley catheter & 1 \\
Bad general condition or old age & 7 \\
\hline
\end{tabular}

Table 3 Number of patients becoming catheterfree after different methods of bladder drainage

\begin{tabular}{lrrr}
\hline Method of bladder drainage & $\begin{array}{c}\text { Total } \\
\text { No. Pat. }\end{array}$ & $\begin{array}{c}\text { No. Pat. } \\
\text { catheterfree }\end{array}$ & $\%$ \\
\hline Indwelling Foley catheter (F.C.) & 48 & 38 & 79 \\
Interm. catheter. (I.C.) & 19 & 18 & 95 \\
F.C. + I.C. & 12 & 12 & 100 \\
Cystostomy & 5 & 5 & 100 \\
Cystostomy + I.C. & 1 & 1 & - \\
? & 2 & 2 & 87 \\
Total No. patients & 87 & 76 & 87 \\
\hline
\end{tabular}

Moreover, as is well known, patients with a complete SC lesion require a longer time to become catheterfree than those with an incomplete SC lesion (Bors 1967, Fam e.o. 1978, Perkash 1974, Vivian and Bors 1974). Therefore only the group of 51 patients with a complete SC lesion was studied in this respect (Table 4). Statistically there is a significant difference between the groups of patients treated with different methods of bladder drainage (Kruskal Wallis test $=\mathrm{p}<0.001$ ).

The best results were obtained with intermittent catheterisation. To exclude additional influences (apart of the method of bladder drainage used), the following groups of patients with a complete SC lesion, were statistically compared:

a) Patients of less than 30 years, between 30 and 50 years and more than 50 years old.

b) Male and female patients.

c) Patients with an upper motor neuron lesion and a lower motor neuron lesion.

d) Paraplegics and tetraplegics.

e) Patients with the SC lesion located at the cervical, dorsal or lumbosacral spine.

No statistically significant difference could be found in the length of the period between the SC injury and the complete independence of urinary catheterisation in each of these comparisons (Mann-Whitney U-test).

\section{Complications}

Only those complications occurring during the first 8 months after the SC lesion were considered.

\section{a. Urinary tract infection}

At arrival. When patients were first seen in our centre the urine was already 
Table 4 Length of time before patients with a complete spinal cord lesion became catheterfree

\begin{tabular}{lcc}
\hline Method of bladder drainage & No. Pat. & $\begin{array}{c}\text { Average No. days before } \\
\text { catheterfree }\end{array}$ \\
\hline Foley cathet. (F.C.) & 27 & $105(41$ to 322$)$ \\
Interm. cathet. (I.C.) & 9 & $38(14$ to 101$)$ \\
F.C. + I.C. & 11 & $60(27$ to 122$)$ \\
Cystostomy & 3 & $175(39$ to 264$)$ \\
Cystostomy + I.C. & 1 & 21 \\
\hline
\end{tabular}

Table 5 Results of urine culture at arrival in patients treated elsewhere $(\mathrm{AB}=$ patient under antibiotic treatment)

\begin{tabular}{lccccc}
\hline & \multicolumn{5}{c}{ Urine culture } \\
\cline { 5 - 6 } Method bladder drainage & Total No. Pat. & Infected & Sterile (AB) & Sterile & Unknown \\
\hline Foley cathet. & 77 & 50 & 20 & 2 & 5 \\
Interm. cathet. & 7 & 4 & 1 & 2 & - \\
Cystostomy & 5 & 2 & 1 & 1 & 1 \\
Unknown & 2 & 1 & 1 & - & \\
Total & 91 & 57 & 23 & 5 & 6 \\
& & $63 \%$ & $25 \%$ & $5 \%$ & $7 \%$ \\
\hline
\end{tabular}

Table 6 Urinary tract infection at discharge in catheterfree patients. $(A B=$ under antibiotic treatment)

\begin{tabular}{lccccc}
\hline & & \multicolumn{4}{c}{ Urine culture } \\
\cline { 3 - 5 } Method bladder drainage & Total No. Pat. & Sterile & Sterile (AB) & Infected & Unknown \\
\hline Foley cathet. (F.C.) & 41 & $23(56 \%)$ & $5(12 \%)$ & $12(29 \%)$ & $1(3 \%)$ \\
Interm. cathet. (I.C.) & 21 & $17(81 \%)$ & - & $4(19 \%)$ & - \\
F.C. + I.C. & 17 & $11(65 \%)$ & - & $6(35 \%)$ & - \\
Cystostomy & 5 & 5 & - & - & - \\
\hline
\end{tabular}

Table 7 Causes for chronicity of urinary tract infection

\begin{tabular}{lcccc}
\hline & & \multicolumn{2}{c}{ Causes for chronic infection } \\
\cline { 3 - 5 } Method bladder drainage & Total No. Pat. & Prostatitis & Residu & Renal calculus \\
\hline Foley cathet. (F.C.) & 7 & 3 & 3 & 1 \\
Interm. cathet. (I.C.) & 2 & -3 & - & 2 \\
F.C. + I.C. & 3 & 2 & 1 & - \\
\hline
\end{tabular}

infected in one of 24 patients who had not received treatment elsewhere and in 57 of 91 patients who had been treated in another hospital (Table 5). In all 20 patients on Foley catheter drainage who had a sterile urine culture at arrival (while taking antibiotics), a significant urinary tract infection occurred within 14 days despite the continued antibiotic treatment. Bacteria in this group of patients were highly resistant. While treated in our centre, all the patients had at least one period of urinary tract infection. 
At discharge 29 per cent of the 110 remaining patients had a urinary tract infection. The frequency of urinary tract infection at discharge was compared in the patients with established micturition and different methods of artificial bladder drainage during spinal shock (Table 6).

In 22 patients the urinary infection proved to be chronic and a cause for this could be diagnosed in 12 patients (Table 7). Most of them had been treated with an indwelling Foley catheter.

\section{b. Urinary sepsis}

Sepsis, caused by urinary tract infection occurred in 21 patients (Table 8). The conditions in which urinary sepsis occurred are listed in Table 9.

Table 8 Frequency of urinary sepsis

\begin{tabular}{lcrr} 
& & \multicolumn{2}{c}{ Urinary sepsis } \\
\cline { 3 - 4 } Method bladder drainage & Total No. Pat. & No. Pat. & $\%$ \\
\hline Foley cathet. (F.C.) & 59 & 12 & $20 \%$ \\
Interm. cathet. (I.C.) & 28 & 2 & $7 \%$ \\
F.C. + I.C. & 20 & 7 & $35 \%$ \\
\hline
\end{tabular}

Table 9 Conditions in which urinary sepsis occurred

\begin{tabular}{lc}
\hline & No. Pat. \\
\hline Foley catheter not clamped & 2 \\
Foley catheter clamped & 9 \\
Within 24 h after taking Foley cath. out & 5 \\
Within 3 days after Foley cath. drainage changed to interm. cathet. & 3 \\
Primary drainage with interm. cathet. & 2 \\
\hline
\end{tabular}

\section{Calculosis}

c. Renal calculi

Early renal calculi (first 8 months post-injury), were found in five patients. All of them had a urinary tract infection. Three of them had been treated with a Foley catheter, one with intermittent catheterisation and one with both FC and IC. In none of these patients were pre-injury X-rays available.

\section{d. Bladder calculi}

These were found in 31 patients $(27 \%)$. The frequency with different methods of bladder drainage is given in Table 10. Urinary tract infection was present in all but one patient.

\section{e. Urethral pathology}

Urethral strictures occurred in two patients. One tetraplegic patient treated with 
Table 10 Frequency of bladder calculi

\begin{tabular}{lccr}
\hline & & \multicolumn{2}{c}{ Bladder calculus } \\
\cline { 3 - 4 } Method bladder drainage & total No. Pat. & No. Pat. & $\%$ \\
\hline Foley cathet. (F.C.) & 59 & 28 & 47 \\
Interm. cathet. (I.C.) & 28 & 2 & 7 \\
F.C. + I.C. & 20 & 2 & 10 \\
Cystostomy & 5 & 1 & 20 \\
\hline
\end{tabular}

cystostomy developed a urethral stricture 6 months after injury. His urethra had possibly been injured at the time of his accident.

In a 16-year-old boy several urethral strictures developed during intermittent catheterisation. Another three had urethral trauma during intermittent catheterisation but none developed a stricture or other permanent lesion of the urethra.

\section{f. Urethral diverticulum}

This developed in three patients after drainage of a para-urethral abscess. All had been treated with a Foley catheter.

\section{g. Epididymitis}

Occurred in seven patients all treated with Foley catheter. In two unilateral orchidectomy was necessary.

\section{h. Chronic prostatitis}

By a specific localisation test (Kuhlemeirer, 1982) chronic prostatitis could be diagnosed in six patients. All had been treated with indwelling Foley catheters.

\section{j. Vesico-ureteral reflux}

During the first 8 months vesico-ureteral reflux was diagnosed by cystometrography (Damanski, 1965) in 12 patients. All had bladder drainage with indwelling Foley catheter during spinal shock. Reflux was bilateral in five and unilateral in seven patients.

\section{k. Autonomic dysreflexia}

In the group of 38 patients with a complete spinal cord lesion above D7, autonomic dysreflexia was noticed in 15. All had been treated with indwelling Foley catheters. Dysreflexia occurred in three patients only while still on Foley catheter drainage. In 12 dysreflexia appeared when Foley catheter drainage was changed to intermittent catheterisation or shortly after patients became catheterfree. 


\section{Discussion}

Drainage of the bladder is very important in the early care of SCI patients. Artificial bladder drainage is mainly done by introducing a catheter as bladder expression by the Crede manoeuvre can be used only in a minority of such patients (Dollfus and Maury, 1981).

The introduction of a urinary catheter can lead to complications and the avoidance of such complications is a main consideration in the treatment of all patients on artificial bladder drainage.

One way to avoid complications is to keep the period of bladder catheterisation as short as possible and in SCI patients this necessitates an early establishment of micturition. In our series those on intermittent catheterisation regained micturition earlier than those treated by any other method. The same conclusion was drawn by other authors (O'Flynn, 1974, Archimbaud and Leriche, 1981).

Pearman and England (1976) found that the highest number of patients became catheter-free if intermittent catheterisation was used. Our results do not allow such a conclusion as we did not find a statistically significant difference in the number of patients becoming catheter-free between the groups treated with different methods of bladder drainage.

Complications were mainly found in the patients on Foley catheter drainage and in this group most of the renal and bladder calculi and urethral lesions were found. In the same group all cases of epididymitis, chronic prostatitis and vesico-ureteral reflux were found. All patients with autonomic dysreflexia in this study had been treated by an indwelling catheter. It is noteworthy that both urinary sepsis and autonomic dysreflexia occurred when continuous indwelling catheter drainage was stopped or changed to another method. In the presence of urinary tract infection such changes in therapy should be done taking all precautions.

Our results related to urinary tract infection do not seem to be as favourable as those published from some other centres. This may be explained by the fact that most of our patients were transferred from other hospitals usually two to three months after their injury and that those patients admitted immediately after injury to our hospital are treated in non-specific departments for an average of 4 weeks. The majority of our patients had a urinary tract infection when arriving at the SCI centre but 73 per cent of the catheterfree patients left the centre without infection ( $6 \%$ under antibiotic treatment). The best results were obtained with intermittent catheterisation and cystostomy. When Foley catheter drainage was used urinary sepsis occurred frequently and urinary tract infection often proved to be incurable. One third of the catheter-free patients who had been treated with an indwelling Foley catheter left the hospital with infection of the urinary tract.

Mainly because of these bad results regarding urinary tract infection the indwelling Foley catheter is no longer used in SCI patients in our hospital.

Fine bore suprapubic cystostomy was used in only five patients in this group. Our experience is limited but the results in these patients were good and complications were rare. We now use this method in patients with SCI combined with cardiovascular problems, traumatic bladder or urethral lesions and prostatic or urethral infections. 
It is not unlikely that this method will become more widely used if favourable results continue to be reported (Peatfield et al., 1983).

We did not compare the cost of treatment in our hospital with different methods of bladder drainage. Barkin et al. (1983) published a comparison between Foley catheter drainage and intermittent catheterisation, and Grundy et al. (1983) compared suprapubic fine bore cystostomy and intermittent catheterisation. Although the choice of a method of bladder drainage should not be conducted mainly on financial criteria, such economic considerations may be important in all countries today. Also in this aspect Foley catheter drainage seems the least favourable.

\section{Résumé}

Quatre différentes méthodes de drainage vésical ont été pratiquées chez 115 paraplégiques au stade initial: la cystostomia minima, la sonde à demeure, le sondage intermittent et les deux dernières méthodes consécutivement.

Le nombre de patients à être libre de sondage n'était pas influencé par la méthode de drainage appliquée. Par contre, la durée de la période du sondage artificiel était influencée par la methode employée d'une manière statistiquement significative. Les paraplégiques traités par sondage intermittent furent les premiers à acquérir un nouveau équilibre vésical.

Peu de complications ont été vues chez les patients traités par sondage intermittent ou cystostomie.

Par contre les complications étaient fréquentes chez ceux traités par une sonde à demeure.

\section{Zusammenfassung}

Bei 115 Querschnittsgelähmten sind, in der Spinalschockperiode, vier verschiedene Blasendrainagemethoden angewendet worden: der suprapublische Katheter mit kleinerem Durchmesser, der Foley-Katheter, der intermittierende Katheterismus und beide letztgenannte Methoden nacheinander.

Die Blasendrainagemethode konnte keinen Einfluss ausüben auf die Anzahl der Patienten, die ohne Katheter auskamen, sie bestimmte jedoch, in einer statistisch deutlich merkbaren Weise, die Dauer der Periode, in der künstliche Blasendrainage vonnöten war. Patienten, die intermittierend katheterisiert wurden, kamen am schnellsten ohne Katheter aus.

Sowohl beim intermittierenden Katheterismus wie beim suprapupischen Katheter taten sich wenig Verwicklungen vor. Bei der Anwendung des Foley-Katheters hingegen sind eine grosse Anzahl von Verwicklungen aufgezeichnet worden.

\section{References}

Archimbaud JP, Leriche A 1981 Le drainage vésical. In: M. Maury (ed) La paraplégie. Flammarion Medecine Sciences, Paris, Ch 15, p 210-214.

Barkin M, Dolfin D, Herschorn S, Bharatwal N, Comisarow R 1983 The urological care of the spinal cord injury patient. Journal of Urology 129:335-339.

BESLEY FA 1917 A plea for the noncatheterisation of the urinary bladder in cases of gunshot wounds of the spinal column. Journal of American Medical Association 69:638-639.

BORS E 1967 Intermittent catherisation in paraplegic patients. Urologia Internationalis 22:236-249.

CURLING TB 1833 Essay on affections of the bladder in paraplegia. London Medical Gazette 13:78-80.

DAMANSKI M 1965 Vesico-ureteric reflux in paraplegia. British Journal of Surgery 52:168-177.

Dollfus P, MAURY M 1981 Les soins spécialisés initiaux: sphincters, rééducation, respiration, articulations. In: M. Maury (ed) La paraplégie, Flammarion Médecine Sciences, Paris, Ch 7, 76-82.

Fam BA, Rossier AB, Blunt K, Gabilondo FB, Sarkarati M, Sethi J, Yalla SV 1978 Experience in the urological management of 120 early spinal cord injury patients. Journal of Urology 119:485-487.

Grundy DJ, Fellows GJ, Gillett AP, Nuseibeh I, Silver JR 1983 A comparison of finé-bore 


\section{PARAPLEGIA}

suprapubic and an intermittent urethral catheterisation regime after spinal cord injury. Paraplegia 21:227-232.

GutTMANN L, Frankel H 1966 The value of intermittent catheterisation in the early management of traumatic paraplegia and tetraplegia. Paraplegia 4:63-83.

HugONET P, Dejerine H 1919 Les grands infirmes par troubles des centres nerveux. Extrait de conférence interalliée pour l'étude de la réeducation professionnelle et des questions qui intéressent les invalides de guerre Paris 1917. Imprimerie Choix Paris, Tome 3.

MAROSSZEKY JE, FaRNSWORTH RH, JONES RF 1973 The indwelling urethral catheter in patients with acute spinal cord trauma. Medical Journal of Australia 2:62-66.

MUNRO D, HAHN J 1935 Tidal drainage of the urinary bladder. New England Journal of Medicine 212:229-237.

O'FLYNN JD 1974 Early management of neuropathic bladder in spinal cord injury. Paraplegia $12: 83-86$

Pearman JW, England EJ 1976 The urinary tract. In: Vinken PJ, Bruyn GW (eds) Handbook of clinical neurology, Vol 26, North Holland Publishing Company, ch 23, p 409-436.

PeatField DRC, BURT AA, SMITH PH 1983 Suprapubic catheterisation after spinal cord injury: a follow-up report. Paraplegia $21: 220-226$.

PERKASH I 1974 Intermittent catheterisation: urologists point of view. Journal of Urology $111: 356-360$.

VeLlaCOTT PN 1919 Spinal injury with retention of urine. The avoidance of catheterisation. Lancet: $733-737$.

VersCHUEREN A 1982 Tidal drainage. In: A. Chantraine (ed) 3è congrès Européen des paramédicaux sur la paraplégie. Médecine et Hygiène, Genève, 13-20.

VIVIAN JM, BORS E 1974 Experience with intermittent catheterisation in the South West Regional system of treatment of spinal injury. Paraplegia 12:158-166. 